\title{
Cell Patterning Method Using Resonance Vibration of a Metallic Cell Cultivation Substrate
}

\author{
Chikahiro Imashiro, ${ }^{*}$ Yuta Kurashina, ${ }^{*}$ Kenjiro Takemura ${ }^{* *}, \#$
}

\begin{abstract}
Spatial control of cell position is essential for numerous studies in tissue engineering, such as generation of linearly patterned muscle tissues, radially patterned liver lobule tissues, and circularly formed anal sphincter. This study proposes a novel method capable of patterning cells in a certain shape on a cell cultivation substrate. The concept is to pattern cells along the nodal position of resonance vibration on a cell cultivation substrate. Note that there are numerous resonance vibrations with different nodal patterns. In this study, we constructed a cell cultivation device consisting of a metallic cell cultivation substrate that can be excited to generate resonance vibration using a piezoelectric ceramic disk glued to the back of the substrate. In this study, we generated resonance vibration with a cross-circle nodal pattern. The cultivation substrate was a $\varnothing 40 \mathrm{~mm} \times 1 \mathrm{~mm}$ stainless steel plate, and the resonance frequency of the vibration was $21.4 \mathrm{kHz}$. Using the device, we conducted cell patterning experiments employing calf chondrocytes using various vibration amplitudes $\left(1.0,1.5\right.$, and $\left.2.0 \mu \mathrm{m}_{\mathrm{p}-\mathrm{p}}\right)$. Cells were cultured for 2 hours. After the experiment, the cell density distribution on the substrate was measured by staining viable cells with calcein. Additionally, we confirmed the viability of the patterned cells after exposure to acoustic pressure produced by the resonance vibration by counting the number of cells attached to the substrate. Viable cells were successfully patterned along the nodal position when the vibration amplitude was $1.5 \mu \mathrm{m}_{\mathrm{p}-\mathrm{p}}$. The number of cells attached to the substrate was $99.2 \%$ of that without vibration. Conversely, when the amplitude was $1.0 \mu \mathrm{m}_{\mathrm{p}-\mathrm{p}}$, the cells were not patterned. The acoustic pressure produced by $1.0-\mu \mathrm{m}_{\mathrm{p}-\mathrm{p}}$ vibration was not large enough to move cells. Similarly, the cells could not be patterned when the amplitude was $2.0 \mu \mathrm{m}_{\mathrm{p}-\mathrm{p}}$. In this case, flow of the culture medium induced by the high acoustic pressure probably prevented the cells from patterning. In conclusion, cells can be patterned along the nodal position of resonance vibration generated with an appropriate vibration amplitude. We believe that this method has great potential for use in tissue engineering.
\end{abstract}

Keywords: cell patterning, resonance vibration, ultrasound, regenerative medicine, tissue engineering.

Adv Biomed Eng. 5: pp. 142-148, 2016.

\section{Introduction}

Spatial control of cell position is crucial for numerous biological studies and applications in tissue engineering and regenerative medicine [1], such as generation of linearly arranged muscle tissues [2], radially arranged liver lobule tissues [3], and circularly formed anal sphincter. Developing such organs would expand the possibility of tissue engineering.

Because cell patterning techniques facilitate a wide variety of applications as mentioned above, a number of studies in various disciplines such as microelectromechanical (MEMS) systems, dielectrophoresis and ultrasonics have been reported [4-7].

Lam et al. [2] cultured myoblasts on a silicone substrate with a wave-patterned surface to form myotubes. Cells were aligned according to the wave pattern. However, the cellular arrangement is limited to the wave pattern formed on a silicone substrate with

This study was presented at the Symposium on Biomedical Engineering 2016, Asahikawa, September, 2016.

Received on July 22, 2016; revised on September 23, 2016; accepted on November 20, 2016.

* School of Science for Open and Environmental Systems, Graduate School of Science and Technology, Keio University, Yokohama, Japan.

** Department of Mechanical Engineering, Faculty of Science and Technology, Keio University, Yokohama, Japan.

\#3-14-1 Hiyoshi, Kohoku-ku, Yokohama 223-8522, Japan.

E-mail: takemura@mech.keio.ac.jp
MEMS technology. Ho et al. [3] arranged liver sinusoid endothelial cells in a radiating pattern using dielectrophoresis to reproduce the morphology of liver lobule. However, the pattern of cells is limited to the shape of the electrode. One of the most widely known cell patterning methods is surface modification [8]. Cells adhere readily to hydrophilic surfaces, but not to hydrophobic surfaces [9]. Cells can be patterned using a hydrophilic-hydrophobic pattern on a cell cultivation substrate [4]. Using these techniques, cells can be patterned in different shapes. However, a major problem is that a specific device can only arrange cells in a certain pattern.

Acoustic tweezers are one of the most promising techniques for directly patterning cells, which can selectively arrange cells in several patterns using one device [7]. When an acoustic pressure wave is applied to a cell cultivation chamber, it generates a pressure distribution pattern with constant positions of nodes and antinodes. Cells are then gathered to the node positions of the wave, where the acoustic pressure is relatively low. This technique is considered to be a noninvasive and high-resolution cell patterning method. However, the possible cell allocation patterns are so far limited to dots, lines, and mesh.

To generate more useful shapes such as circular and radiating shapes noninvasively using one device, we focused on the resonance vibration modes of the cell cultivation substrate itself. As the resonance vibration mode of a cell cultivation substrate is generated, cells may be gathered to the node position of the vibration mode, because the substrate hardly vibrates at the node position but mainly vibrates at the antinode position [10]. An attrac- 


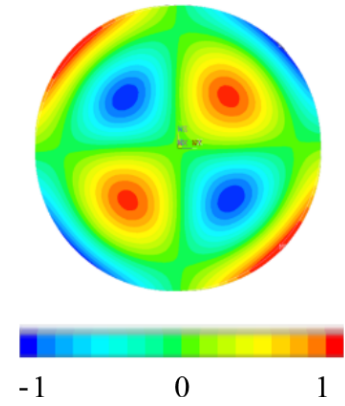

Fig. 1 Eigenvalue analysis (ANSYS 15.0). Colored bar indicates outof-plane displacement normalized to the maximum amplitude (vibration frequency, $26.9 \mathrm{kHz}$ ).

tive feature is that a plate or a substrate has an infinite number of resonance vibration modes with various node shapes [11]. This concept is based on Chladni figure formation [12] of particles scattered on a plate and trapped to the node positions of resonance vibration generated on the plate. Ultimately, we can align cells to a variety of node shapes such as linear, circle, and radiating shapes, by selectively generating different vibration modes in a cell cultivation substrate, although more complicated substrate design may be required.

We have reported the basic concept of this cell patterning method at an international conference [13]. In our previous report, we patterned cells in a circular shape. The present report demonstrates in detail the cell patterning method and the relationship between the distributions of vibration amplitude and cell density on the cultivation substrate. In this study, the resonance vibration mode of the cell cultivation substrate had a cross-circle nodal pattern (Fig. 1), which was different from the resonance vibration mode with a single nodal circle used in our previous study [13]. Together with our previous report, this study may reveal the efficiency of selectively generating resonance vibrations in a cultivation substrate to arrange cells in various shapes.

\section{Design and fabrication}

Figure 2 shows the cell cultivation device. The device consisted of a metallic cultivation substrate capable of generating a resonance vibration mode with cross-circle nodal pattern (Fig. 1), an acrylic cover, acrylic base, silicone rubber wall, and silicone rubber base, assembled with stainless steel bolts and nuts. The cultivation substrate was sandwiched between the silicone rubber wall and silicone rubber base. The inner diameter of the silicone rubber wall corresponded to that of the nodal circle, so that the vibration amplitude would not be damped significantly by the silicone rubber wall. The cultivation chamber was $36 \mathrm{~mm}$ in diameter and $5 \mathrm{~mm}$ in depth.

A detailed explanation of the substrate design and the method to generate resonance vibration effectively are given in Supplement S1. Using this resonance vibration mode, cells seeded on the cultivation substrate may be trapped to the nodal cross position that can be considered as the simplest form of radiating shape (Fig. 3).

We evaluated the vibration performance of the cell cultivation device. The resonance vibration mode with the cross-circle nodal pattern was generated on the cultivation substrate by applying an $\mathrm{AC}$ voltage to the piezoelectric ceramic disk. The vibration

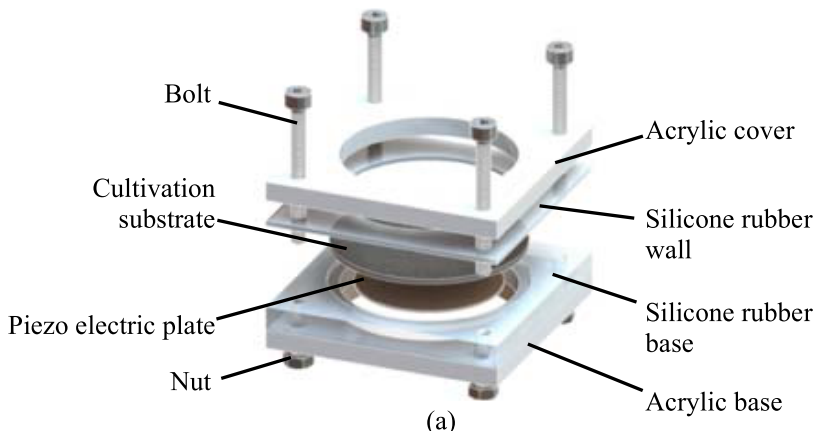

(a)

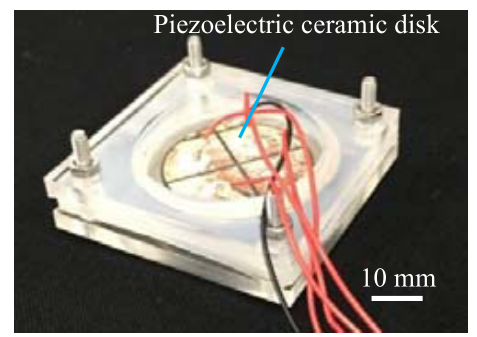

(b)

Fig. 2 Cell cultivation device. (a) Exploded view. (b) Bottom view.

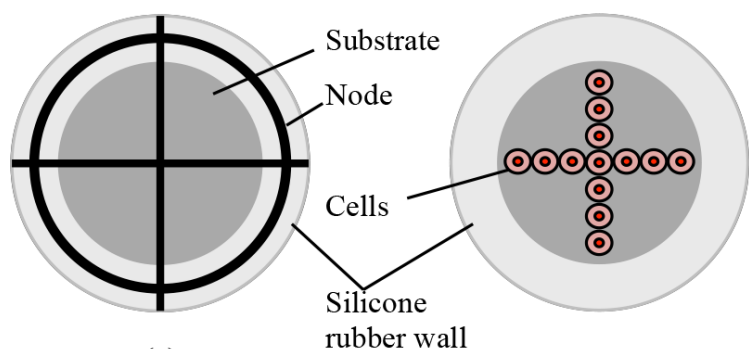

(a)

(b)

Fig. 3 Cell manipulation using resonance vibration. (a) Node shape. (b) Shape of patterned cells.

velocity of the cultivation substrate was measured using a laser Doppler vibrometer (LV-1800, ONO SOKKI, Japan). To mimic the cultivation condition during measurement, the cell cultivation chamber was filled with $2 \mathrm{~mL}$ of culture solution. Figure $\mathbf{4}$ shows the relationship between the driving frequency and maximum amplitude with a driving voltage of $30 \mathrm{~V}_{\mathrm{p}-\mathrm{p}}$. Note that the amplitude was normalized to the maximum value. Based on this result, we measured the amplitude distribution on the cell cultivation substrate with a driving voltage of $30 \mathrm{~V}_{\mathrm{p}-\mathrm{p}}$ and driving frequency of $21.4 \mathrm{kHz}$.

The amplitude distribution was measured along the antinode/node directions as shown in Fig. 5. Figure 6 compares the measured and analyzed amplitude distributions. Note that the vibration amplitude was normalized to the maximum amplitude. Figure 6 suggests that the resonance vibration mode with a cross-circle nodal pattern was successfully generated on the cell cultivation substrate. The correlation coefficients between the measured and analyzed data were 0.93 for the antinode direction and 0.86 for the node direction.

\section{Experimental methods of cell patterning}

We used calf chondrocytes in this study. Cell preparation is ex- 


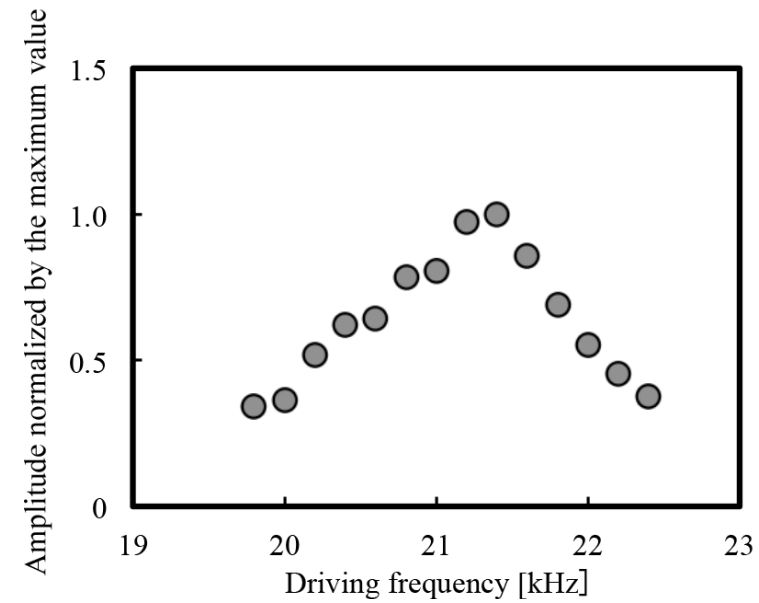

Fig. 4 Relationship between driving frequency and normalized vibration amplitude (voltage, $30 \mathrm{~V}_{\mathrm{p}-\mathrm{p}}$ ). The amplitude is in out-ofplane direction and normalized to the maximum value at resonance.

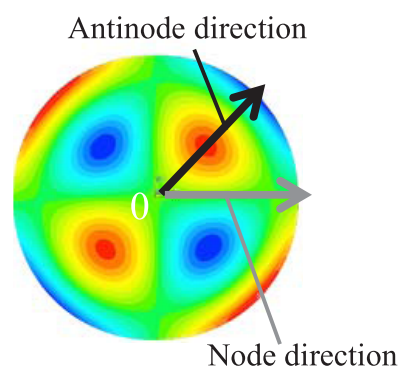

Fig. 5 Directions for amplitude measurement, antinode direction, and node direction.

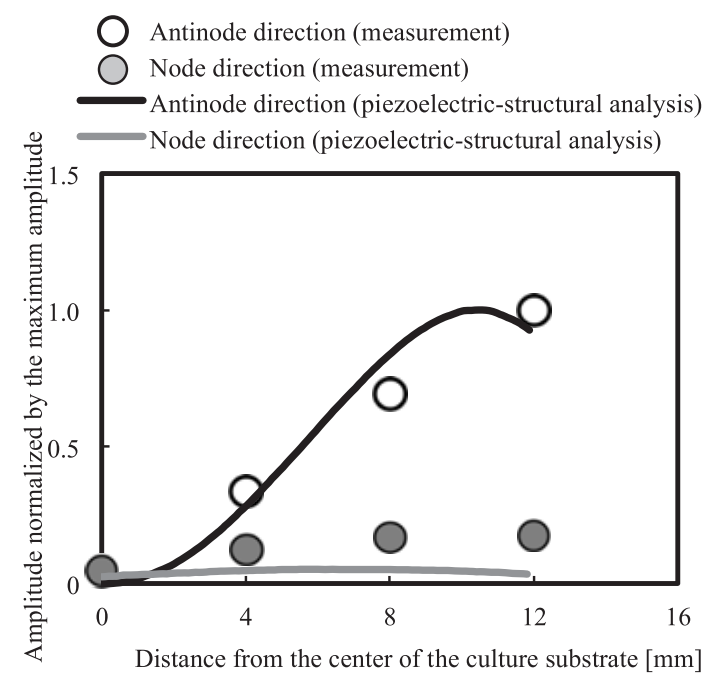

Fig. 6 Amplitude distributions obtained by piezoelectric structural analysis.

plained in Supplement S2. Cells were patterned on the substrate using resonance vibration. The maximum amplitude of the resonance vibration was set at $1.0,1.5$, and $2.0 \mu \mathrm{m}_{\mathrm{p}-\mathrm{p}}$ by adjusting the driving voltage. This amplitude setting was based on our previous study [10]. Cell patterning experiments were performed as follows.

\subsection{Effect of vibration amplitude on cell distribution}

Cells were seeded into the cultivation chamber and incubated at $37^{\circ} \mathrm{C}$ with $5 \% \mathrm{CO}_{2}$ for 3 minutes. The number of seeded cells was $5.0 \times 10^{4}\left(2.5 \times 10^{4}\right.$ cells $\left./ \mathrm{mL}\right)$, which was less than confluent on the cell cultivation substrate to provide enough space for the cells to move.

The resonance vibration with a cross-circle nodal pattern was generated on the cultivation substrate for 2 hours to manipulate the cells. The frequency was set at $21.4 \mathrm{kHz}$, corresponding to the resonance frequency of the vibration mode.

After incubation for 2 hours, viable cells remaining on the substrate were stained with calcein (C0875, Sigma-Aldrich), and the cell density was measured at each location along the antinode/ node directions shown in Fig. 5. Before staining, the medium was removed from the cell cultivation chamber and the remaining cells were washed twice with phosphate-buffered saline (PBS).

\subsection{Effect of vibration amplitude on cell adhesion}

After 2 hours of incubation, we counted the number of cells floating in the medium and the number cells attached to the cell cultivation substrate to confirm cell viability after exposure to the resonance vibration. The cells floating in the medium were counted using a hemocytometer after the medium was removed from the chamber. After removal of the medium, the attached cells were washed twice with PBS. Then, the attached cells were detached from the substrate by trypsinization, and the cell number was counted using a hemocytometer.

\section{Results and discussion}

Figure 7 shows the cell distributions at various vibration amplitudes. The cell density was normalized to the average cell density obtained without vibration. Note that cell density could not be measured up to $16 \mathrm{~mm}$ from the center because of the edge of the silicone rubber wall. Therefore, the measurement range was up to $12 \mathrm{~mm}$. Figure 7 shows that when the maximum amplitude of the resonance vibration was 1.0 or $2.0 \mu \mathrm{m}_{\mathrm{p}-\mathrm{p}}$, the cell distribution showed no clear relationship with the amplitude distribution. At the lower amplitude $\left(1.0 \mu \mathrm{m}_{\mathrm{p}-\mathrm{p}}\right)$, the cells were not effectively manipulated because the acoustic pressure was not high enough to manipulate the cells. At the higher amplitude $\left(2.0 \mu \mathrm{m}_{\mathrm{p}-\mathrm{p}}\right)$, the cells also could not be patterned, because a strong flow of the medium was induced by the vibration $[7,14]$. This acoustic streaming flow prevented the cells from coming in contact with the substrate.

However, at the appropriate vibration amplitude $\left(1.5 \mu \mathrm{m}_{\mathrm{p}-\mathrm{p}}\right)$, more cells were observed near the node position than near the antinode position. The stained cells exposed to the resonance vibration at a maximum amplitude of $1.5 \mu \mathrm{m}_{\mathrm{p}-\mathrm{p}}$ are shown in Fig. 8. Few cells were found near the antinode position [Fig. 8(a-3, a-4)]. Additionally, a boundary between the cell-attaching and -detaching areas was observed [Fig. 8(a-3)]. Figure 9 shows the relationship between normalized cell density and vibration amplitude for resonance vibration with maximum amplitude of $1.5 \mu \mathrm{m}_{\mathrm{p}-\mathrm{p}}$. Note that the cell density was normalized to the average density without vibration. ANOVA with multiple comparison using Ryan's method was used to confirm significant difference. In addition, the amplitudes in Fig. 9 were measured at the points 


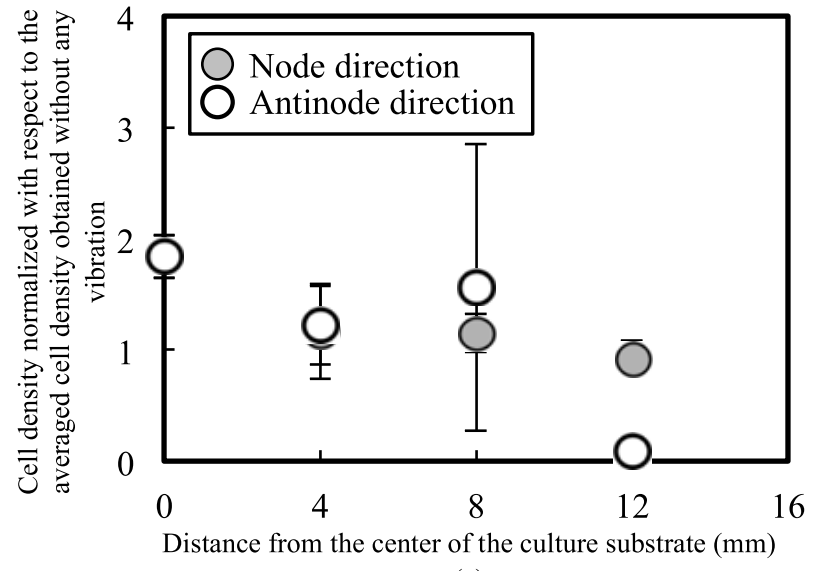

(a)

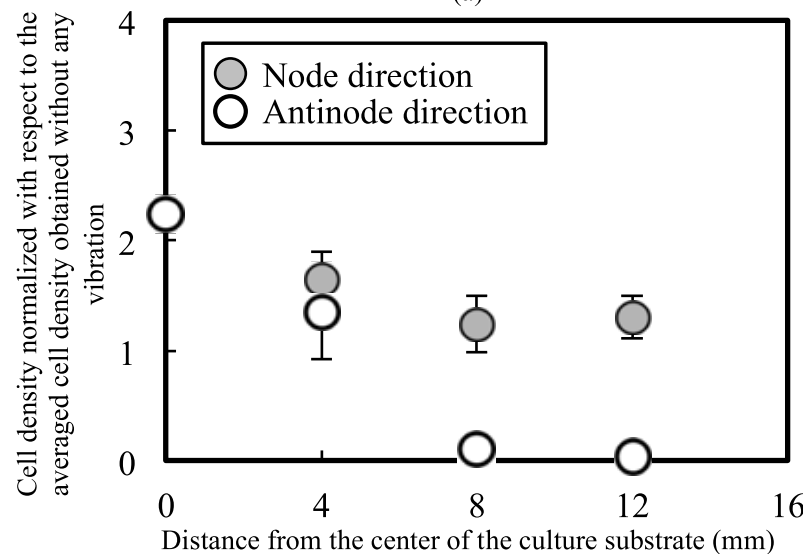

(b)

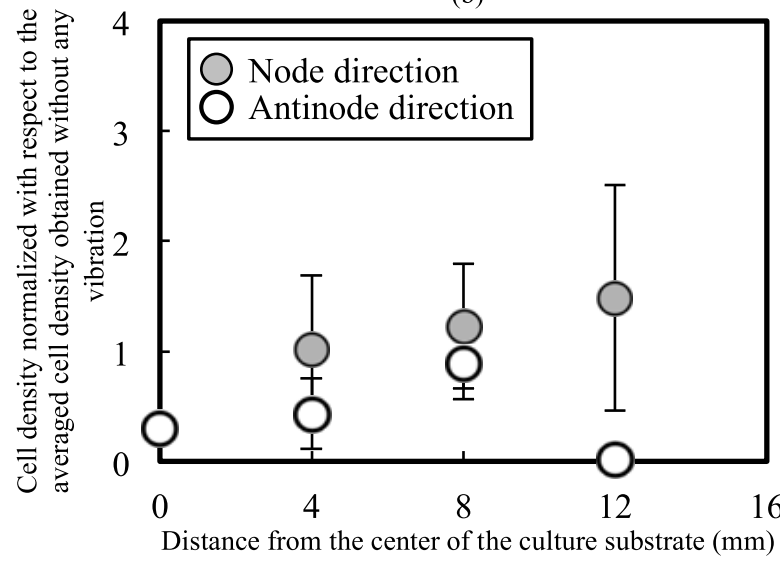

(c)

Fig. 7 Cell patterning results with a maximum amplitude of (a) $1.0 \mu \mathrm{m}_{\mathrm{p}-\mathrm{p}}$, (b) $1.5 \mu \mathrm{m}_{\mathrm{p}-\mathrm{p}}$, and (c) $2.0 \mu \mathrm{m}_{\mathrm{p}-\mathrm{p}}$. Cell density was normalized to cell density without vibration (mean \pm standard deviation, $n=4)$.

shown in Fig. 5. Linear regression was conducted for amplitudes of $1.0 \mu \mathrm{m}_{\mathrm{p}-\mathrm{p}}$ and lower, since the amplitude of $1.0 \mu \mathrm{m}_{\mathrm{p}-\mathrm{p}}$ was obviously the threshold for cell manipulation. The vibration amplitude was inversely related to the cell density, indicating that the cell distribution was related to the amplitude distribution.

Although cells could be aligned along the node position at the appropriate vibration amplitude $\left(1.5 \mu \mathrm{m}_{\mathrm{p}-\mathrm{p}}\right)$, we can improve the cell patterning accuracy by reducing the acoustic streaming flow. According to previous studies [15], acoustic streaming flow generation is caused by damping of the acoustic wave, which de-
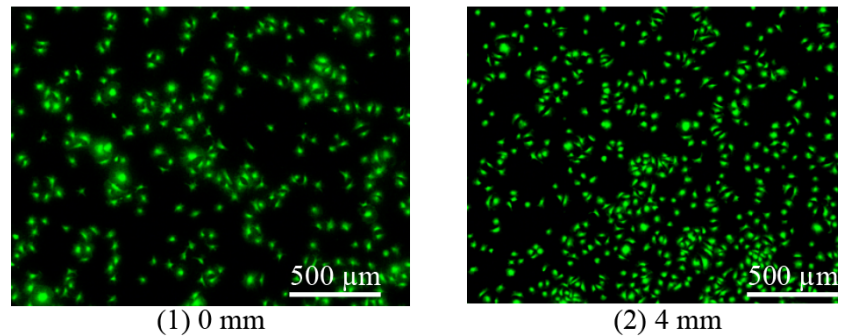

(2) $4 \mathrm{~mm}$
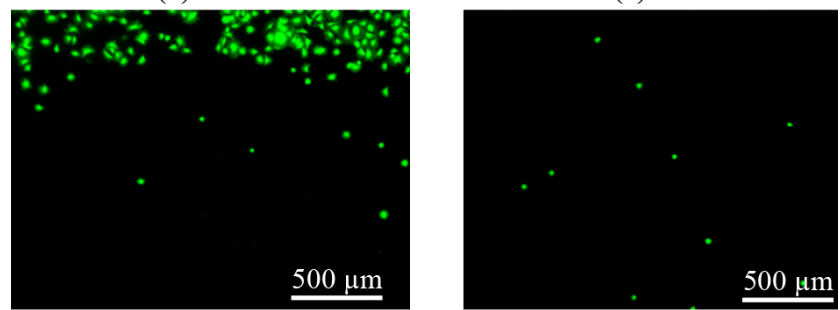

(3) $8 \mathrm{~mm}$

(a)

(4) $12 \mathrm{~mm}$
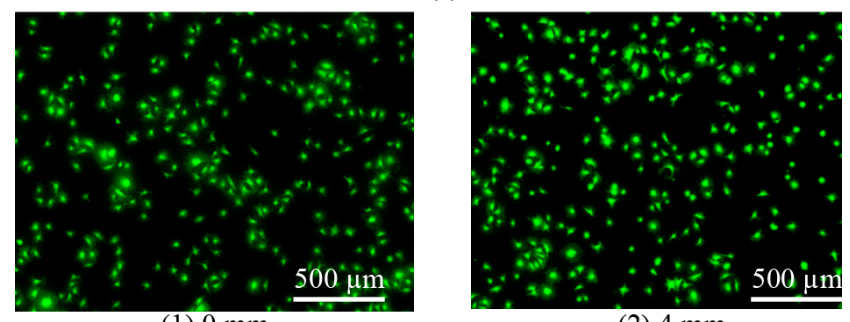

(1) $0 \mathrm{~mm}$

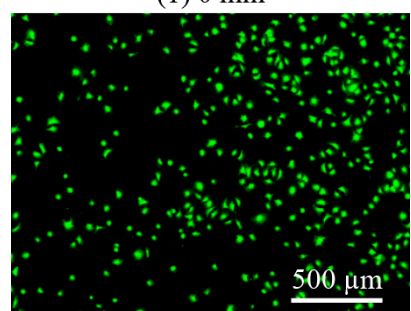

(2) $4 \mathrm{~mm}$

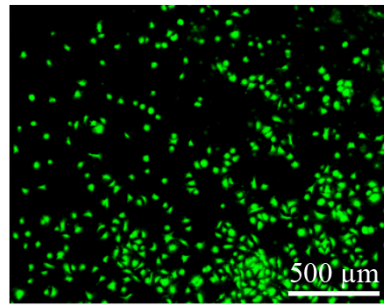

(4) $12 \mathrm{~mm}$

(b)

Fig. 8 Cells stained with calcein after cell manipulation at a maximum amplitude of $1.5 \mu \mathrm{m}_{\mathrm{p}-\mathrm{p}}$. (a) Along the antinode direction. (b) Along the node direction.

pends on the driving frequency and the distance of acoustic wave propagation. To maintain a weak acoustic flow, we will use a much lower frequency and fill the cultivation chamber with a smaller volume of medium in our future study.

Figure 10 shows the number of cells remaining on the substrate and the number floating in the medium. Almost all the cells were attached to the cell cultivation substrate at the selected vibration amplitude of $1.5 \mu \mathrm{m}_{\mathrm{p}-\mathrm{p}}$. This result suggests that most of the cells exposed to the acoustic radiation pressure remained alive on the cell cultivation substrate. If the cells were dead, they would not adhere to the substrate. Moreover, there was no significant difference in the number of cells attached to the cell cultivation substrate among all conditions. Hence, we conclude that cells can be patterned from the antinode position to the node position by the resonance vibration without any cell loss. This study demonstrates that cells can be patterned to form a cross shape on the cell cultivation substrate using resonance vibration. Together with our previous study [13], cells can be patterned in plural shapes using one device. Notably, to change the pattern, only a change in the driving frequency of the input $\mathrm{AC}$ signals is required. In addition, 


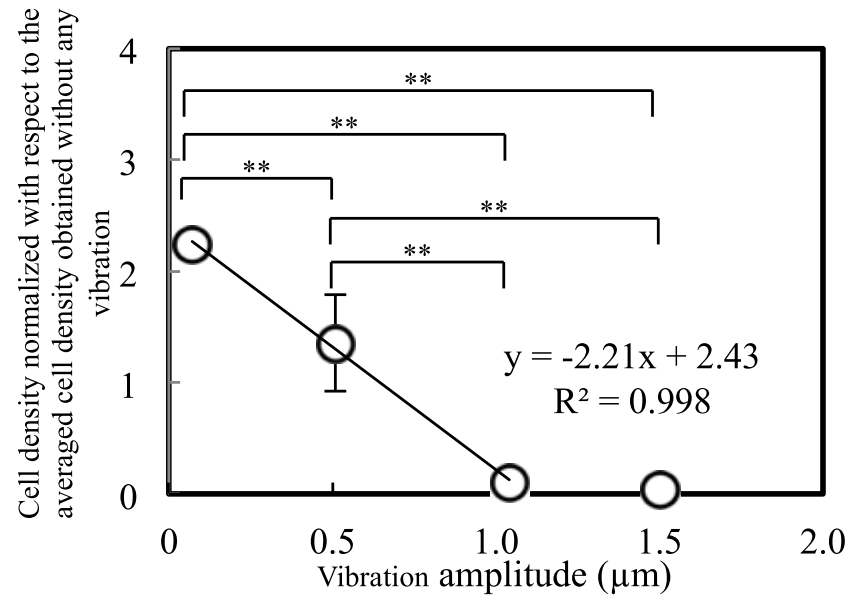

Fig. 9 Normalized cell density as a function of vibration amplitude at a maximum amplitude of $1.5 \mu \mathrm{m}_{\mathrm{p}-\mathrm{p}}$. Cell density was measured along the antinode direction and normalized to the cell density without vibration (mean \pm standard deviation, $n=4,{ }^{* *}$ : $p<0.01)$. Linear regression is conducted using the data with amplitudes of $1.0 \mu \mathrm{m}_{\mathrm{p}-\mathrm{p}}$ and lower since the amplitude of $1.0 \mu \mathrm{m}_{\mathrm{p}-\mathrm{p}}$ is obviously the threshold for cell manipulation.

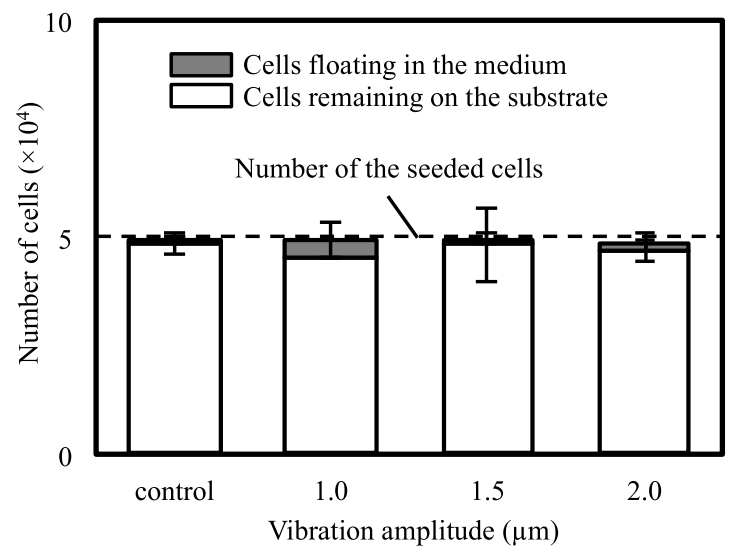

Fig. 10 Comparison of adhered and floating cell numbers after cell patterning (mean \pm standard deviation, $n=3$ ).

the shapes of the patterned cells (circle and cross) are useful for several biological studies and applications such as generation of anal sphincter and liver lobule tissues that have not been selectively patterned by a single device.

In our future study, we will attempt to pattern cells on a commercially available disposable cell cultivation dish made of plastic material. Although we used a metallic substrate to prove our concept, any substrate, even plastic material, has resonance vibrations. Additionally, the resonance frequency will be lower in general with plastic substrates, which would reduce the acoustic flow and possibly increase the cell patterning ability. Viability of cells after exposure to resonance vibration also requires detailed confirmation.

\section{Conclusion}

We propose a novel cell patterning method using the resonance vibration of a cell cultivation substrate. We designed and fabricat- ed a cell cultivation device that can generate resonance vibration with a cross-circle nodal pattern on the cell cultivation substrate. Using this device, we demonstrated that viable calf chondrocytes can be patterned along the node of the resonance vibration generated on the cell cultivation substrate, when the vibration amplitude is set at an appropriate value. We believe that this technique has great potential for use in tissue engineering and regenerative medicine.

\section{Conflict of Interest}

We have no conflicts of interest or relationships with any companies or commercial organizations based on the definition of the Japanese Society of Medical and Biological Engineering.

\section{Acknowledgments}

This work was supported in part by JSPS KAKENHI Grant Number JP16H04259 and a MEXT Grant-in-Aid for the Program for Leading Graduate Schools.

\section{References}

1. Huh D, Kim HJ, Fraser JP, Shea DE, Khan M, Bahinski A, Hamilton G, Ingber DE: Microfabrication of human organs-on-chips. Nat Protoc. 8(11), pp. 2135-2157, 2013.

2. Lam MT, Sim S, Zhu X, Takayama S: The effect of continuous wavy micropatterns on silicone substrates on the alignment of skeletal muscle myoblasts and myotubes. Biomaterials. 27(24), pp. 4340-4347, 2006.

3. Ho CT, Lin RZ, Chen RJ, Chin CK, Gong SE, Chang HY, Peng HL, Hsu L, Yew TR, Chang SF, Liu CH: Liver-cell patterning Lab Chip: mimicking the morphology of liver lobule tissue. Lab Chip. 13(18), pp. 3578-3587, 2013.

4. Ueda E, Levkin PA: Emerging applications of superhydrophilic-superhydrophobic micropatterns. Adv Mater. 25(9), pp. 12341247, 2013.

5. Ostrovidov S, Hosseini V, Ahadian S, Fujie T, Parthiban SP, Ramalingam M, Bae H, Kaji H, Khademhosseini A: Skeletal muscle tissue engineering methods to form skeletal myotubes and their applications. Tissue Eng. Part B Rev. 20(5), pp. 403-436, 2014.

6. Voldman J: Electrical forces for microscale cell manipulation. Annu Rev Biomed Eng. 8(1), pp. 425-454, 2006.

7. Gesellchen F, Bernassau L, Déjardin T, Cumming DRS, Riehle MO: Cell patterning with a heptagon acoustic tweezer - application in neurite guidance. Lab Chip. 14, pp. 2266-2275, 2014.

8. Singhvi R, Kumar A, Lopez GP, Stephanopoulos GN, Wang DI, Whitesides GM, Ingber DE: Engineering cell shape and function. Science. 264(5159), pp. 696-698, 1994.

9. Okano T, Yamada N, Okuhara M, Sakai H, Sakurai Y: Mechanism of cell detachment from temperature-modulated, hydrophilic-hydrophobic polymer surfaces. Biomater Silver Jubil Compend. 16(4), pp. 109-115, 2006.

10. Kurashina Y, Takemura K, Miyata S, Komotori J, Koyama T: Effective cell collection method using collagenase and ultrasonic vibration. Biomicrofluidics. 8(054118), 2014.

11. Shi X, Shi D, Li WL, Wang Q: A unified method for free vibration analysis of circular, annular and sector plates with arbitrary boundary conditions. J Vib Control. 22(2), pp. 442-456, 2016.

12. Okuda A, Ono T: Bracing effect in a guitar top board by vibration experiment and modal analysis. Acoust Sci Technol. 29(1), pp. 103-105, 2008.

13. Imashiro C, Kurashina Y, Takemura K, Miyata S, Komotori J: Cell manipulation by nodal circle resonance vibration of a cell 
cultivation substrate. Proc of IEEE Ultrason. Symp 2015, Taipei, pp. 10-13, 2015

14. Bernassau L, Glynne-Jones P, Gesellchen F, Riehle M, Hill M, Cumming DRS: Controlling acoustic streaming in an ultrasonic heptagonal tweezers with application to cell manipulation. Ultrasonics. 54(1), pp. 268-274, 2014.

15. Shilton RJ, Travagliati M, Beltram F, Cecchini M: Nanoliter-droplet acoustic streaming via ultra high frequency surface acoustic waves. Adv Mater. 26(29), pp. 4941-4946, 2014.

\section{S1. Cell cultivation substrate capable of generating a resonance vibration}

The design of the substrate was as follows. To generate resonance vibration in cell cultivation substrate effectively, we designed a substrate made of AISI SUS316L stainless steel. This substrate has higher Young modulus and lower damping than the plastic materials often used as cell cultivation substrates, allowing generation of resonance vibrations in the ultrasonic frequency range. Eventually, efficient acoustic pressure can be generated against cells. Note that the biocompatibility of AISI SUS316L stainless steel as a cell cultivation substrate has been confirmed [S1]. However, fine particle peening treatment was first conducted on the top surface on which the cells were cultured. Rendering the surface enhances cell proliferation comparable to a conventional plastic cell cultivation surface [S2].

We calculated the resonance vibration modes of the metal cultivation substrate using the finite element method (ANSYS 15.0, ANSYS, Canonsburg, PA, USA). The cultivation substrate was a $\varnothing 40 \mathrm{~mm} \times 1 \mathrm{~mm}$ plate. Its material properties are shown in Tables S1 and S2. Using the results of the eigenvalue analysis, we adopted an out-of-plane resonance vibration mode with a cross-circle nodal pattern to pattern cells (Fig. 1), which had a resonance frequency of $26.9 \mathrm{kHz}$. In addition to the substrate, the cultivation device should be able to hold culture medium on the cell cultivation substrate. Therefore, a silicone rubber wall was placed on the edge of the cell cultivation substrate. Using this resonance vibration mode, cells seeded on the cultivation substrate may be trapped to the nodal cross position that can be con-

Table S1 Physical properties of the stainless steel and adhesion layer used in finite element analysis.

\begin{tabular}{ccc}
\hline & The stainless steel & Adhesion layer \\
\hline Young's modulus $(\mathrm{Pa})$ & $19.3 \times 10^{10}$ & $2.5 \times 10^{9}$ \\
Poisson's ratio & 0.3 & 0.4 \\
Density $\left(\mathrm{kg} / \mathrm{m}^{3}\right)$ & $7.98 \times 10^{3}$ & $2.30 \times 10^{3}$ \\
\hline
\end{tabular}

sidered the simplest shape of radiating shapes (Fig. 4).

To excite the substrate to generate this resonance vibration mode, we designed a piezoelectric ceramic disk (Fig. S1) that was glued to the back of the cultivation substrate. The top face of the disk, which was in contact with the substrate, had a uniform electrode, whereas the bottom mainly had quarter-circle electrodes. The small electrode regions next to areas $\mathrm{C}$ and $\mathrm{D}$ were used to sense the vibration and ground the top face of the disk, respectively. By applying AC signals to electrodes A-D at a frequency corresponding to the resonance vibration $(26.9 \mathrm{kHz})$, resonance vibration that produced the cross-circle nodal pattern was generated. Note that the temporal phase of the signal to areas A and C must shift by $\pi$ from that of the input signal to areas B and D.

We confirmed the appropriateness of our piezoelectric ceramic disk by piezoelectric-structural analysis using the finite element method (ANSYS 15.0). Our finite element model consisted of the metal substrate and piezoelectric ceramic disk. In between the substrate and disk, we modeled a 0.02-mm-thick epoxy adhesion layer. An AC voltage of $10 \mathrm{~V}_{\mathrm{p}-\mathrm{p}}$ was applied to the piezoelectric ceramic disk with the temporal phase shift mentioned above. The resonance vibration mode with the cross-circle nodal pattern, shown in Fig. 1, was successfully generated at a frequency of $26.9 \mathrm{kHz}$.

Based on this design, we fabricated a cell cultivation substrate (Fig. S2) capable of generating the resonance vibration mode with the cross-circle nodal pattern shown in Fig. 1. A piezoelectric ceramic disk (C-203, Fuji Ceramics, Shizuoka, Japan) was glued to the bottom of the substrate with epoxy adhesive (16223, Konishi, Osaka, Japan) under $3 \mathrm{~N} / \mathrm{m}^{2}$ pressure for 1 hour. To input AC voltage to the piezoelectric ceramic disk, lead wires were soldered to each quarter-circle electrode.

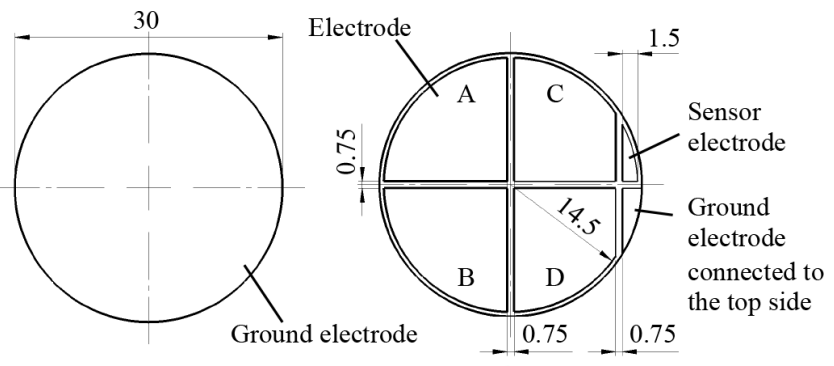

(a)

(b)

Fig. S1 Electrode pattern of the piezoelectric ceramic disk (0.5-mm thick). Polarization is along the thickness direction. (a) Top face on which the cultivation substrate was glued. (b) Bottom face. Unit: $\mathrm{mm}$.

Table S2 Anisotropic elastic matrix of the piezoelectric material used in finite element analysis $\left(\mathrm{N} / \mathrm{m}^{2}\right)$.

\begin{tabular}{ccccccc}
\hline & $X$ & $Y$ & $Z$ & $X Y$ & $Y Z$ & $Z X$ \\
\hline$X$ & $10.35 \times 10^{10}$ & $5.09 \times 10^{10}$ & $5.09 \times 10^{10}$ & 0 & 0 & 0 \\
$Y$ & $5.09 \times 10^{10}$ & $10.35 \times 10^{10}$ & $5.09 \times 10^{10}$ & 0 & 0 & 0 \\
$Z$ & $5.09 \times 10^{10}$ & $5.09 \times 10^{10}$ & $10.35 \times 10^{10}$ & 0 & 0 & 0 \\
$X Y$ & 0 & 0 & 0 & $2.63 \times 10^{10}$ & 0 & 0 \\
$Y Z$ & 0 & 0 & 0 & 0 & $2.63 \times 10^{10}$ & 0 \\
$Z X$ & 0 & 0 & 0 & 0 & 0 & $2.63 \times 10^{10}$ \\
\hline
\end{tabular}




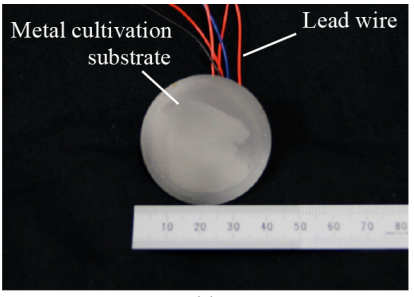

(a)

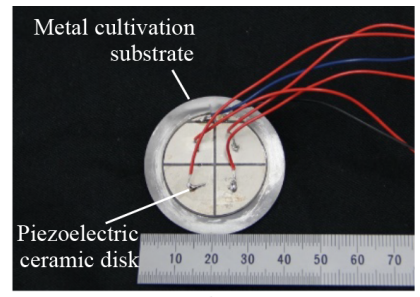

(b)
Fig. S2 Cell cultivation substrate: (a) Top surface on which the cells were cultivated. (b) Bottom surface.

The method for exciting resonance vibration was as follows. When AC signals were applied to electrodes A-D at the resonance frequency, resonance vibration was generated to produce the cross-circle nodal pattern.

The frequency response of the cell cultivation substrate is shown in Fig. 4, indicating that the resonance frequency was $21.4 \mathrm{kHz}$, which was $20 \%$ lower than that analyzed. The difference was mainly due to modeling error and the presence of culture medium in the cell cultivation chamber.

\section{S2. Cell preparation}

To prepare the target cells, cartilage was dissected from knee joints of 4-6-week-old calves under sterile conditions. The target cells, calf chondrocytes, were isolated from the extracellular matrix by sequential incubation for 18 hours at $37^{\circ} \mathrm{C}$ in Dulbecco's modified Eagle's medium/Nutrient F-12 Ham (DMEM/F12) (D8900, Sigma-Aldrich, St. Louis, MO, USA) supplemented with $10 \%$ fetal bovine serum (FBS; S1820, Biowest SAS, Nuaillé, France), $0.15 \%$ collagenase type I (C0130, Sigma-Aldrich), and antibiotic-antimycotic (15240, Thermo Fisher Scientific, Carlsbad, CA, USA). The cells were then isolated by centrifugation, resuspended, and cultured in growth medium (DMEM/F12 supplemented with $10 \% \mathrm{FBS}$ ) in a humidified $5 \% \mathrm{CO}_{2}$ incubator at $37{ }^{\circ} \mathrm{C}$. Cell passaging was performed every 3 days by trypsinization in $0.05 \%$ trypsin-ethylene-diaminetetraacetic acid (25300, Thermo Fisher Scientific).

\section{References}

S1. Kikuchi S, Kameyama Y, Mizutani M, Komotori J: Effects of fine particle peening on oxidation behavior of nickel titanium shape memory Alloy. 55(1), pp. 176-181, 2014.

S2. Nakai S, Miyata S, Komotori J: Effect of complex stimuli of shear stress and surface modification on proliferation and phenotype of chondrocyte. J Jpn Inst Met. 79(6), pp. 324-329, 2015.

\section{Chikahiro IMASHIRo}

Chikahiro Imashiro received his B.E. degree in Mechanical Engineering from Keio University, Yokohama, Japan in 2015. He is currently a Master course student in Micro/Nano-Mechatronics laboratory of Keio University since 2014 . He is a research assistant of Leading Graduate Schools pro-

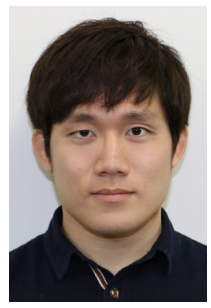
gram in Japan from 2015. His research interests are on ultrasonic transducers, tissue engineering and biomedical devices.

\section{Yuta Kurashina}

Yuta Kurashina received his B.E. degree in Mechanical Engineering and M. E. degree in Integrated Design Engineering from Keio University, Yokohama, Japan in 2012 and 2014, respectively. He is currently a Ph.D. candidate in Micro/Nano-Mechatronics laboratory of Keio University

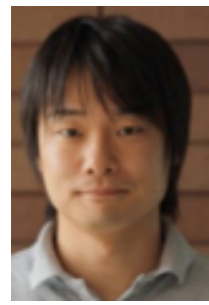
since 2014. He was a research assistant of Leading Graduate Schools program in Japan from 2014 to 2015 . He is also a doctoral course student (DC) of Japan Society for the Promotion of Science (JSPS) research fellowships from 2015. He received a JSMS Award for Best Presentation in 2012, a MSSJ Prize for Outstanding Achievement 2013, a Best Paper Award at the ASME International Mechanical Engineering Congress \& Exposition in 2015, etc. His research interests are on biomedical devices, ultrasonic transducers and biomaterials.

\section{Kenjiro TAKEMURA}

Kenjiro TAKEMURA received his B.E. degree in Mechanical Engineering and M.E. degree in Biomedical Engineering from Keio University, Yokohama, Japan in 1998 and 2000, respectively. He also received his Ph.D. degree in integrated design engineering from Keio University in 2002. He was with

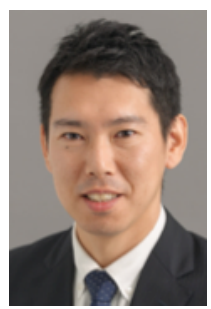
the Department of Mechanical Engineering at Keio University in 2002 as a Research Associate, with the Precision and Intelligence Laboratory at Tokyo Institute of Technology as an Assistant Professor from 2003 to 2008. He has been with the Department of Mechanical Engineering at Keio University since 2008 where he is currently an Associate Professor. He received a JSME Young Engineers Award in 2002 for a research on Multi-DOF ultrasonic motor, a Best Research Paper Award at the 10th International Conference on Mechatronics Technology in 2006, a Best Paper Award at the ASME International Mechanical Engineering Congress \& Exposition in 2015, etc. His research interests are on ultrasonic transducers, functional fluids, haptic interface, and biomedical devices. 